\title{
SÍNTESE ENZIMÁTICA DE BIODIESEL A PARTIR DO ÓLEO DE COCO EM REATORES DE LEITO FIXO, DOIS ESTÁGIOS, INCORPORANDO UMA COLUNA EXTRATORA DE GLICEROL
}

\author{
W. COSTA SILVA, L. RAMOS, L. F. TEIXEIRA, H. F. de CASTRO \\ Escola de Engenharia de Lorena, Departamento de Engenharia Química (EEL-USP) \\ E-mail para contato: larissa@ dequi.eel.usp.br
}

\begin{abstract}
RESUMO - O objetivo deste trabalho foi desenvolver um processo eficiente de síntese enzimática de biodiesel em reator de leito fixo (PBR), dois estágios, incorporando uma coluna extratora de glicerol, operando em regime contínuo. Como modelo de estudo foi selecionado a reação de transesterificação do óleo de coco com etanol, em meio isento de solvente a $50{ }^{\circ} \mathrm{C}$ empregando como biocatalisador lipase de Burkholderia cepacia imobilizada em matriz híbrida sílica-PVA. O desempenho do reator foi avaliado para substrato constituído de óleo de coco na razão molar óleo: etanol de 1:12, na vazão volumétrica de $0,78 \mathrm{~mL} \cdot \mathrm{h}^{-1}$ correspondendo a um tempo espacial de $14 \mathrm{~h}$, exibindo rendimentos médios de 98,0 $\pm 1,45 \%$ e produtividade de $41,1 \pm 1,5 \mathrm{mg} \cdot \mathrm{g}^{-1} \cdot \mathrm{h}^{-1}$. As amostras de biodiesel purificadas apresentaram viscosidade cinemática média de 5,5 $\pm 0,3$ $\mathrm{mm}^{2} \cdot \mathrm{s}^{-1}$, atendendo as normas vigentes pela resolução ANP $\mathrm{n}^{\circ} 14 / 2012$, que estabelece viscosidade cinemática do B100 na faixa entre $3,0-6,0 \mathrm{~mm}^{2} \cdot \mathrm{s}^{-1}$. O biocatalisador foi estável quanto suas características morfológicas e catalíticas, revelando tempo de meiavida de $520 \mathrm{~h}$.
\end{abstract}

\section{INTRODUÇÃO}

Industrialmente, o biodiesel é produzido pela transesterificação alcalina de óleos vegetais e gordura animal com metanol, em razão das altas taxas de rendimento em curto período reacional, além do baixo custo do catalisador $(\mathrm{NaOH})$. Entretanto, este método apresenta limitações, como difícil recuperação do catalisador, elevada geração de águas residuárias e alto custo nas etapas de purificação do biodiesel (Christopher et al., 2014). Logo, o uso de enzimas na indústria tem atraído atenção, em especial o uso de enzimas na forma imobilizada em razão dos benefícios oferecidos, como: possibilidade de recuperação, reutilização do biocatalisador e a condução em fluxo contínuo.

Diferentes configurações de reatores têm sido usadas em estudos com lipases, entre as quais, os reatores de leito fixo (PBR), são os mais utilizados (Hama et al., 2013). Esse tipo de reator proporciona maior área superficial para a reação, por unidade de volume, do que um reator de membrana e é cineticamente mais favorável que os reatores contínuos com agitação. Portanto, os reatores PBR vêm sendo implementados com êxito na síntese enzimática de biodiesel a partir de diferentes matérias-primas (Hama et al., 2011). Entretanto, o acúmulo de glicerol (subproduto da 


\section{9 a 22 de outubro de 2014 \\ Florianópolis/SC}

reação) no leito catalítico reduz a eficiência da enzima, uma vez que a adsorção de compostos polares no suporte de imobilização causa limitações difusionais e inibição da lipase, devido a formação de uma camada hidrofílica ao redor da enzima, o que dificulta o acesso ao substrato hidrofóbico e afeta a eficiência da catálise (Gog et al., 2012). Para superar estas dificuldades, diferentes estratégias de remoção do glicerol vêm sendo investigadas, entre as quais pode ser destacada a incorporação de colunas extratoras recheadas com diferentes materiais, como a resina Lewatit GF 202, que já demonstrou eficiência comprovada na metanólise contínua do óleo de soja (Hama et al., 2011).

Desta forma, uma configuração de reatores PBR, dois estágios, com incorporação de uma coluna extratora de glicerol (Lewatit GF 202) foi selecionada para o desenvolvimento deste trabalho. A matéria-prima lipídica selecionada foi o óleo de coco, devido a sua ampla disponibilidade no território brasileiro. Como doador do grupo acila foi utilizado etanol em função das vantagens oferecidas em relação ao metanol (Carvalho et al., 2013).

\section{MATERIAIS E MÉTODOS}

\subsection{Materiais}

Lipase comercial de Burkholderia cepacia foi adquirida da Amano Enzyme Inc. (Nagoya, Japão), e em seguida imobilizada em suporte híbrido polissiloxano-álcool polivinílico $\left(\mathrm{SiO}_{2}-\mathrm{PVA}\right)$, sintetizado pela técnica sol-gel (Carvalho et al., 2013) originando derivados imobilizados com atividade média de $2134 \pm 64 \mathrm{U.g}^{-1}$. Como materiais de partida foram utilizados: etanol anidro (98\%, Cromoline), óleo de coco adquirido da Fres-Coco (São Paulo), tendo composição aproximada em ácidos graxos de: 8,9\% Caprílico, 6,2\% Cáprico, 47,1\% Láurico, 18,8\% Mirístico, 7,9\% Palmítico, 2,6\% Esteárico, 6,1\% Oleico e 1,6\% Linoleico. Outros reagentes: solventes (tert-butanol e hexano, Cromoline), álcool polivinílico (88\%, Acros Organics), $\mathrm{HCl}$ (mínimo 36\%, Isofar), epicloridrina $\left(99 \%\right.$, Aldrich $\left.^{\circledR}\right)$, polietilenoglicol (MM 1500, Synth), tetraetilortossilicato (98\%, Aldrich ${ }^{\circledR}$ ), goma arábica em pó pura (Sinth) e óleo de oliva comercial com baixo teor de acidez (Carbonell). Corante lipossolúvel azul (pigmento orgânico sintético manufaturado por Glitter Ind. Com. Imp. Exp. Ltd., Carapicuíba- SP) foi adquirido em mercado local e usado como traçador. Corante alimentício Amaranto adquirido da Sigma-Aldrich (Brasil) foi utilizado nos testes de adsorção do glicerol no suporte. Lewatit ${ }^{\circledR}$ GF202 (resina macroporosa com densidade de 1,24 g.L ${ }^{-1}$ e capacidade de adsorção $250 \mathrm{~g}$ glicerol. $\mathrm{L}^{-1}$ ) foi gentilmente cedida pela Lanxess (Leverkusen, Alemanha).

\subsection{Síntese contínua de biodiesel em reator PBR conectados em série}

A síntese de biodiesel foi realizada em duas colunas de vidro encamisadas (diâmetro interno = $15 \mathrm{~mm}$, comprimento $=55 \mathrm{~mm}$ e volume $=10 \mathrm{~mL}$ ), conectadas em série, conforme ilustrado na Figura 1. O substrato composto por óleo de coco e etanol (razão molar óleo: etanol de 1:12) foi mantido em um frasco de alimentação, sob agitação magnética $(150 \mathrm{rpm})$ e temperatura de $50{ }^{\circ} \mathrm{C}$. $\mathrm{O}$ substrato foi bombeado através dos reatores contendo $7,8 \mathrm{~g}$ da lipase de B. cepacia imobilizada em $\mathrm{SiO}_{2}$-PVA (carregamento catalítico de $20834 \mathrm{U}$ ) em cada um, com o auxílio de uma bomba peristáltica (SJ-1211-Atto) na vazão requerida. Para evitar perda de etanol no sistema, foi acoplado um condensador de refluxo ao frasco de alimentação. Na saída do primeiro reator foi acoplada uma 
coluna de vidro (diâmetro $=15 \mathrm{~mm}$, altura $=50 \mathrm{~mm}$, volume $=8,0 \mathrm{~mL}$ ) contendo Lewatit ${ }^{\circledR}$ GF202 para adsorção do glicerol formado. O tempo espacial (teórico) foi calculado de acordo com Levenspiel (2000). Amostras foram recolhidas para monitoramento do processo. Ao final do experimento a enzima foi recuperada e lavada com terc-butanol para remoção de substrato e produtos eventualmente retidos nas partículas da matriz e a atividade residual quantificada.

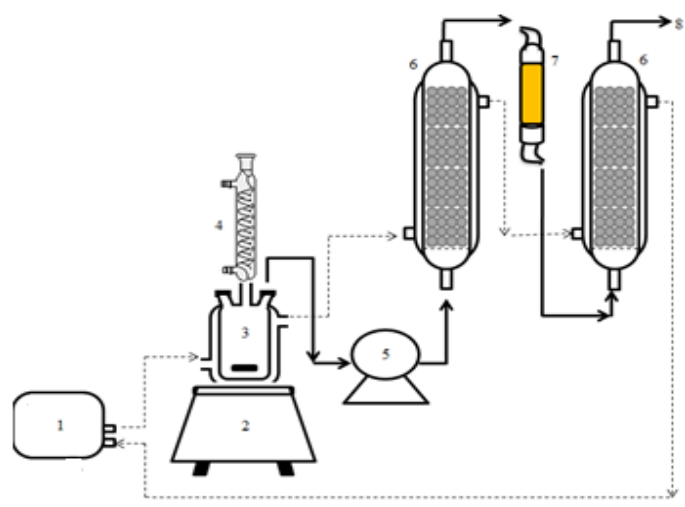

Figura 1 - Aparato experimental dos reatores PBR duplo estágio: 1- Banho termostático, 2- Agitador magnético, 3- Frasco de alimentação, 4- Condensador de refluxo, 5- Bomba peristáltica, 6- Reator tipo leito fixo, 7- Coluna extratora de glicerol; 8- Saída de produto.

\subsection{Métodos de Análise}

Atividade hidrolítica: A atividade hidrolítica da lipase imobilizada foi determinada pelo método de hidrólise do azeite de oliva, conforme metodologia modificada por Soares et al. (1999). A constante de desativação térmica e o tempo de meia-vida do biocatalisador foram calculados conforme descrito por Costa-Silva (2013).

Dosagem dos ésteres de etila: Os ésteres de etila foram monitorados por cromatografia em fase gasosa (Varian 3800), conforme metodologia estabelecida por Urioste et al. (2008). O rendimento das reações de síntese de biodiesel foi definido como o valor que expressa a massa total obtida de ésteres de etila em relação à massa teórica esperada de ésteres de etila.

Purificação das amostras de biodiesel: As amostras retiradas foram purificadas conforme metodologia descrita por Carvalho et al. (2013) e submetidas às análises de densidade e viscosidade.

Determinação da viscosidade e densidade do biodiesel: Os valores da viscosidade absoluta dos produtos purificados, assim como os valores de densidade dos ésteres de etila foram medidos conforme metodologia descrita por Carvalho et al. (2013).

Determinação da função de Distribuição do Tempo de Residência (DTR): A função DTR, E(t) e o tempo médio de residência $\left(t_{m}\right)$, que corresponde ao tempo espacial experimental $(\tau)$ foram determinados de acordo modelagem proposta por Fogler (2002). 


\section{9 a 22 de outubro de 2014 \\ Florianópolis/SC}

\section{RESULTADOS}

\subsection{Função distribuição de tempo de residência (DTR) no reator de duplo estágio}

A DTR exibida por um determinado reator fornece indícios claros do tipo de mistura que ocorre em seu interior e é uma das maneiras mais adequadas de se caracterizar um reator (Fogler, 2002). O cálculo da função DTR e posteriormente do tempo médio de residência $\left(\mathrm{t}_{\mathrm{m}}\right)$, que equivale ao tempo espacial experimental $(\tau)$, foi determinado de acordo com modelagem proposta por Fogler (2002), sendo encontrado um tempo médio de residência de 21,64 h. Este valor foi superior ao tempo espacial (teórico) calculado pela razão entre o volume útil do biorreator e a vazão volumétrica requerida sobre a seção transversal da coluna, que foi de $14 \mathrm{~h}$. Contudo, esta diferença pode ser explicada em função dos volumes considerados em cada caso. O conceito de tempo espacial calculado teoricamente considera apenas o volume do reator onde ocorre a catálise enzimática, não levando em consideração as conexões dos reatores dispostos em série, e muito menos o volume útil da coluna extratora de glicerol, que contém a resina Lewatit. Nesse contexto, considerando todo o aparato experimental e recalculando o tempo espacial (teórico) pela Equação 1, tem-se:

$$
\tau=\frac{\text { Vútil }_{\mathrm{a}}+\text { Vútil }_{\mathrm{b}}+\text { Vútil }_{\mathrm{c}}}{\mathrm{V}}=20,70 \mathrm{~h}
$$

Em que: Vútil $l_{\mathrm{a}}=$ Volume útil do primeiro reator PBR; Vútil $\mathrm{b}_{\mathrm{b}}=$ Volume útil do segundo reator PBR; Vútil $=$ Volume útil da coluna extratora de glicerol; $v$ = vazão requerida no processo.

O valor corrigido do tempo espacial (teórico) foi similar ao determinado no teste traçador $\left(\mathrm{t}_{\mathrm{m}}\right)$. A similaridade entre os tempos espaciais pode ser considerada como um bom indicativo da inexistência de caminhos preferenciais ou zonas mortas no reator, demonstrando uma boa mistura e dinâmica adequada dos reagentes no leito catalítico (Fogler, 2002).

\subsection{Efeito do glicerol na etanólise contínua no reator PBR}

Visando verificar a influência do glicerol, formado como subproduto na reação de transesterificação, no leito catalítico, foi empregado o método de tingimento pelo corante Amaranto descrito por $\mathrm{Xu}$ et al. (2011). Essa técnica mostrou-se adequada para elucidar o comportamento do glicerol na etanólise do óleo de colza, sendo verificada a partição do glicerol in situ e seu acúmulo sobre a lipase imobilizada (Xu et al., 2011).

Tomando por base esse procedimento, testes foram conduzidos para verificar a afinidade do glicerol pela lipase de B.cepacia imobilizada em $\mathrm{SiO}_{2}$-PVA. As fotos ilustradas na Figura 2 mostram a afinidade do glicerol (indicado pela presença do corante de cor vermelha) durante a investigação no sistema multifásico. Observando as fotos (1) e (7), verifica-se que o glicerol apresentou afinidade tanto para o suporte híbrido $\left(\mathrm{SiO}_{2}\right.$-PVA), quanto para a lipase de B. cepacia imobilizada em $\mathrm{SiO}_{2}-$ PVA. 


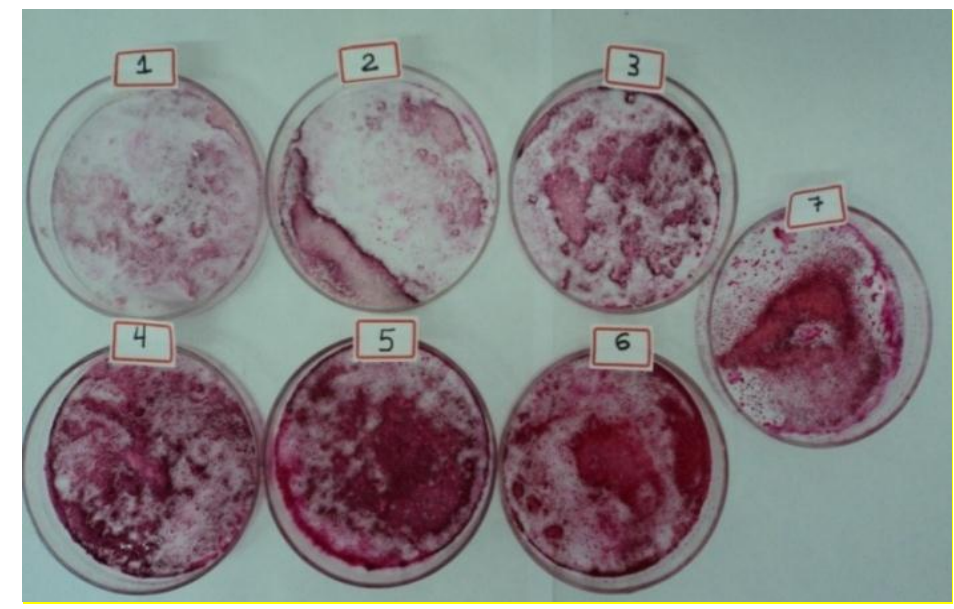

Figura 2 - Afinidade do glicerol pelo suporte de $\mathrm{SiO}_{2}$-PVA e pela lipase imobilizada em $\mathrm{SiO}_{2}-\mathrm{PVA}$ (derivado imobilizado): (1) derivado imobilizado e $0 \%$ glicerol; (2) derivado imobilizado e $2 \%$ glicerol; (3) derivado imobilizado e $4 \%$ glicerol; (4) derivado imobilizado e $6 \%$ glicerol; (5) derivado imobilizado e $8 \%$ glicerol;

(6) derivado imobilizado e $10 \%$ glicerol; (7) suporte $\mathrm{SiO}_{2}$-PVA e $10 \%$ glicerol.

Para reduzir os impactos negativos do acúmulo do glicerol no leito catalítico, foi proposto investigar o desempenho de uma configuração de reator PBR em duplo estágio, incorporando uma coluna de vidro recheada com a resina Lewatit ${ }^{\circledR}$ GF 202 para remoção do glicerol.

\subsection{Etanólise do óleo de coco em PBR duplo estágio empregando a estratégia de separação do glicerol}

No sistema experimental proposto verificou-se que a concentração em ésteres de etila no primeiro estágio variou de 44,9 a 53,4 \% (m.m $\left.\mathrm{m}^{-1}\right)$ correspondendo a rendimentos de transesterificação de 74,8 a $89,0 \%$, enquanto no segundo estágio a concentração de ésteres variou de 56,4 a 59,3\% $\left(\mathrm{m} . \mathrm{m}^{-1}\right)$ correspondendo a rendimentos de transesterificação de 94 a $100 \%$ e produtividade volumétrica de 37,5 a 42,4 $\left(\mathrm{mg}_{\text {éster }} \cdot \mathrm{g}^{-1}\right.$ meio $\cdot \mathrm{h}^{-1}$ ) (Figura 3). Os valores obtidos no segundo estágio são $20 \%$ superiores aos alcançados no primeiro estágio. De acordo com a Figura 3, a conversão total do óleo nos ésteres correspondentes foi alcançada em dois tempos espaciais (28 h), permanecendo constante por um período de 5 dias. Após 144 h, foi constatado um leve declínio da conversão, apresentando $94 \%$ de rendimento médio.

Os elevados valores de rendimento obtidos na etanólise do óleo de coco, permitiram obter amostras de biodiesel com valores de viscosidade média de 5,5 $\pm 0,3 \mathrm{~mm}^{2} . \mathrm{s}^{-1}$, valor que atende as normas vigentes pela resolução ANP $n^{\circ} 14 / 2012$, que estabelece viscosidade cinemática do B100 na faixa entre $3,0-6,0 \mathrm{~mm}^{2} \cdot \mathrm{s}^{-1}$. 


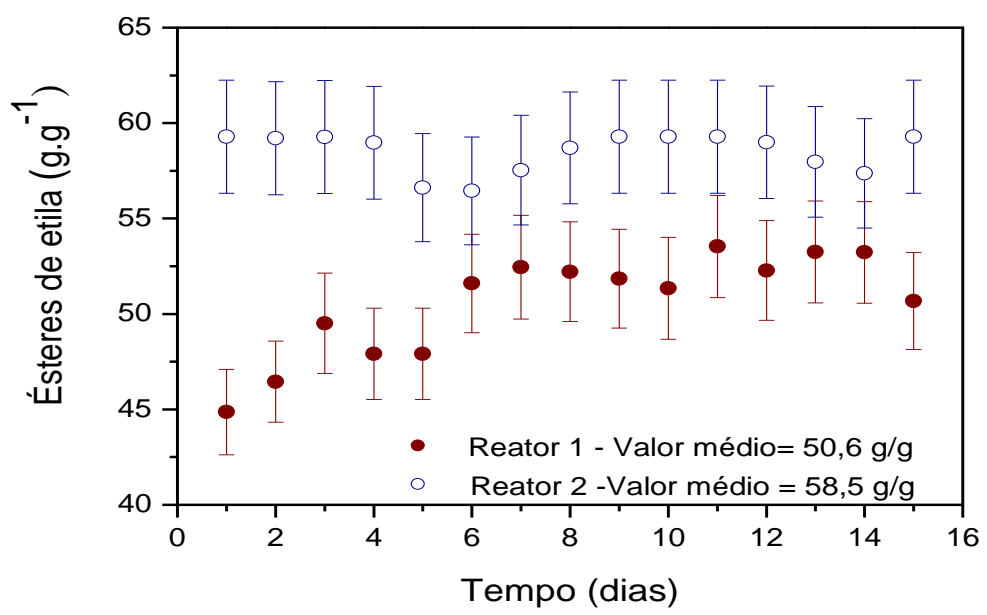

Figura 3 - Formação dos ésteres de etila no efluente do primeiro e do segundo reator PBR, na etanólise contínua do óleo de coco em reator PBR duplo estágio, mediada pela lipase B. cepacia imobilizada em $\mathrm{SiO}_{2^{-}}$ PVA, em meio isento de solvente, empregando tempo espacial de $14 \mathrm{~h}$.

De acordo com os resultados apresentados, o desempenho global do sistema operacional foi satisfatório quando comparado com dados da literatura. Em trabalho realizado por Hama et al. (2011) foram reportados valores de rendimento de biodiesel superiores a $90 \%$ na metanólise enzimática do óleo de soja em reatores PBR, conectados em série, ao longo de 550 h de operação.

Destaca-se ainda que a incorporação da coluna extratora de glicerol (Lewatit GF202) reduziu a limitação difusional e a inativação da enzima imobilizada no segundo reator PBR, promovendo um incremento na formação dos ésteres de etila em relação ao primeiro reator PBR. Além disso, possibilitou a operação estável do sistema reacional, não sendo detectada nenhuma evidência de problemas de perda de desempenho do reator em função da atividade catalítica do leito. Este fato foi confirmado por meio da quantificação da atividade hidrolítica ao final do experimento, em que foi constatada uma perda global de 38,2\% em relação à atividade hidrolítica inicial, obtendo-se valor de $1,3 \mathrm{~h}^{-1}$ para a constante de desativação e tempo de meia-vida do biocatalisador de $520 \mathrm{~h}$.

\section{CONCLUSÃO}

Os resultados obtidos demonstraram que é possível operar um sistema contínuo para produção enzimática de biodiesel a partir do óleo de coco empregando uma configuração de reatores PBR conectados em série na ausência de solventes. Além disso, a estratégia de incorporação de um sistema para remoção do glicerol no efluente do primeiro reator minimizou os problemas de limitação difusional e inativação da lipase imobilizada no segundo reator. A estratégia adotada contribuiu para que o derivado imobilizado atingisse elevada estabilidade operacional (tempo de meia-vida de $520 \mathrm{~h}$ ), possibilitando a obtenção de um produto final adequado, apresentando rendimento em ésteres de etila superior a $94 \%$ e viscosidade média de $5,5 \pm 0,3 \mathrm{~mm}^{2} \cdot \mathrm{s}^{-1}$. 


\section{AGRADECIMENTOS}

Os autores agradecem a CAPES e ao CNPq pelo suporte financeiro.

\section{REFERÊNCIAS}

CARVALHO, A. K. F; DA RÓS, P. C. M; FREITAS, L; ANDRADE, G. S. S; ZANIN, G. M; DE CASTRO, H. F. Assessing the potencial non-edible oils and residual fat to be used as a feedstock in the enzymatic ethanolysis reaction. Ind. Crop. Prod, v. 50, p. 485-493, 2013.

CHRISTOPHER, L. P; KUMAR, H; ZAMBARE, V. P. Enzymatic biodiesel: Challenges and opportunities. Appl. Energy, v. 119, p, 497-520, 2014.

COSTA SILVA, W. Produção enzimática de biodiesel a partir de óleos láuricos em reatores de leito fixo duplo estágio incorporando coluna extratora do glicerol formado como subproduto. 2013. 133p. Dissertação (Mestrado em Ciências) - Escola de Engenharia de Lorena, Universidade de São Paulo.

FOGLER, H. S. Distribuições de Tempos de Residência para Reatores Químicos. In: FOGLER, H. S. Elementos de engenharia das reações químicas, 3 a Ed. Rio de Janeiro: LTC, 2002. Cap. 13. p. 744-802.

GOG, A; ROMAN, M; TOSA, M; PAIZS, C; IRIMIE, F.D. Biodiesel production using enzymatic transesterification - Current state and perspectives. Renew Energ, v.39, p. 10-16, 2012.

HAMA, S; TAMALAMPUDI, S; YOSHIDA, A; TAMADANI, N; KURATANI, N; NODA, H; FUKUDA, H; KONDO, A. Enzymatic packed-bed reactor integrated with glycerol-separating system for solvent-free production of biodiesel fuel. Biochem Eng J, v. 55, p. 66-71, 2011.

HAMA, S; KONDO, A. Enzymatic biodiesel production: An overview of potential feedstocks and process development. Bioresource Technol, v. 135, p. 386-395, 2013.

LEVENSPIEL, O. Chemical Reaction Engineering, 2nded. New York: John Wiley, 2000.

SOARES, C. M. F.; DE CASTRO, H. F.; MORAES, F. F.; ZANIN, G. M. Characterization and utilization of Candida rugosa lipase immobilized on controlled pore silica. Appl. Biochem. Biotechnol., v.77-9, p. 745-757, 1999.

URIOSTE, D., CASTRO, M. B. A., BIAGGIO, F. C., DE CASTRO, H. F. Síntese de padrões cromatográficos e estabelecimento de método para dosagem da composição de ésteres de ácidos graxos presentes no biodiesel a partir do óleo de babaçu. Quim Nova, v. 31, p. 407-412, 2008.

XU, Y; NORDBLAD, M; NIELSEN, P. M; BRASK, J; WOODLEY, J. M. In situ visualization and effect of glycerol in lipase-catalyzed ethanolysis of rapeseed oil. J. Mol. Catal. B: Enzym, v. 72, p. 213-219, 2011. 